\title{
Managerial Empowerment and Its Impact on Managerial Creativity: An Empirical Study in Greater Amman Municipality
}

\author{
Nehaya Nawaf Al Homud ${ }^{1}$ \\ ${ }^{1}$ Department of Business Administration, Zarqa University, Jordan \\ Correspondence: Nehaya Nawaf Al Homud, Department of Business Administration, Zarqa University, Jordan. \\ E-mail: nalhomud@zu.edu.jo
}

Received: June 8, 2020

doi:10.5539/ijbm.v15n11p32
Accepted: August 14, 2020

Online Published: October 20, 2020

URL: https://doi.org/10.5539/ijbm.v15n11p32

\begin{abstract}
Many organizations have collapsed due to lack of creativity and others have also made giant strides due to the creative and innovative ideas of the managers. Hence, creativity is important concept that can change the fortunes of organizations. This study has been conducted to examine the impact of the managerial empowerment on managerial creativity in Greater Amman Municipality. Managerial empowerment has been taken as independent variable. Freedom of choice, self-efficacy, and development of job has been used as the proxy dimensions of managerial empowerment. Moreover, managerial creativity has been taken as dependent variable. Creativity in the product, marketing creativity, and regulatory creativity have been used as the proxy dimensions of managerial creativity. Questionnaires have been used to collect data. The results highlighted that all the dimensions of managerial empowerment are statistically significant on the creativity in the product. The study recommended that proper attention should be paid to the empowerment of workers, especially in the lower administrative levels by encouraging them to take on responsibilities and to look at their mistakes in order to enhance the potential for creativity in Greater Amman Municipality.
\end{abstract}

Key words: managerial empowerment, managerial creativity, Greater Amman Municipality.

\section{Introduction}

Change is the only constant thing in this world. Business environment is dynamic in nature. There is continuous change in government policies, change in taste and choice of the consumer, change in technology, change in international environment, etc. Such changes could be triggered by internal or external factors and it can affect the growth even the survival of business. Managerial creativity is one of the important tools that can change the managerial fortunes of organizations. Good managerial creativity is no doubt, a good tonic for organizational success. Organizations must pay attention and care to manage and develop creativity as it will have a significant impact on its survival and growth.

\section{Managerial empowerment}

\subsection{Concept of Managerial empowerment}

Empowerment is giving individuals the greatest responsibility for decision-making. It is the management style, through which managers and other organizational members share to influence the decision-making process. It is the cooperation in the decision-making process which is not determined by the official centers of power but determined by information systems, training systems, rewarding, participation in the power, style of leadership and organizational culture. Empowerment is to involve decision-making power between management and individuals in a manner that encourages individuals at all organizational levels to participate in decision-making (Zhang \& Zhou, 2014).

Empowerment is the guiding of individual activities towards the various challenges through the internal sense of ability and control, and the existence of sense to link individual goals to the organizational objectives. It includes trust, power, sharing information and decision-making, responsibility and accountability and depends on four combined elements information, knowledge, bonuses, and power (Aburuman, 2016).

Empowerment is a modern management technique for managing HR that help to exploit the potential of employees and self-motivate them by providing certain elements in their jobs, such as the meaning, power, and influence. These incentives for self-stimulation lead to satisfy the basic needs of the individual, such as 
self-assertion, which stimulates creativity and innovation and thus achieve the organization's goals efficiently. This method of self-stimulation depends on the development of the organizations physically and juridical. The vision of empowerment is to develop a strong and capable workforce with a productive capacity for services and goods that exceed consumer expectations.

\subsection{Dimensions of Managerial Empowerment}

\subsubsection{Freedom of Choice}

The sense of individual freedom towards the way of functioning and creativity is one of the modern methods of management in promotion of creativity. Thus, senior management plays a key role in the development of management by encouraging creativity by empowering employees with the power to have the ability and accurate knowledge of the problems surrounding their business areas. It reflects a sense of individual freedom towards the way of functioning, and the extent to allow him to change the tangible and intangible aspects of the organization, to include freedom of choice causal responsibility for personal events. (Kui et al., 2017) see that empowerment Proactive behavior has been associated with empowering leadership, where managers share power with their subordinates and grant them a fair amount of autonomy .

Freedom of choice leads to increased flexibility and innovation. It has a significant impact on the concept of empowerment, and it is necessary to ensure the availability of the desire of the individual to accept this freedom and then take responsibility and the consequences of their choice. The delegating authority to employees means responsibility to assume the risk of their decisions and responsibility for failing to achieve goals and carry out tasks. Thus, the process of creative thinking and the emergence of new ideas and unfamiliar new work methods are essential for the development of the organization.

From the point of view of (Ghejan \& Gal, 2017), the delegating authority to employees, means responsibility to assume the risk of their decisions and responsibility for failing to achieve goals and carry out tasks. Thus, the process of creative thinking and the emergence of new ideas and unfamiliar new work methods are essential for the development of the organization.

\subsubsection{Self-Efficacy}

(Cattaneo \& Chapman, 2010) asserts that self-efficacy as an essential element of empowerment, they define it as: "It means that individuals believe possessing the skills necessary to perform their duties well. Self-efficacy is one of the pillars of the empowerment concept, because giving individual greater responsibilities and powers will not be considered empowerment the individual, unless he has confidence in his ability to succeed in controlling those responsibilities.

(Zhang \& Zhou, 2014) define creative self-efficacy as "the degree to which the employees themselves believed they are capable of being creative". For their part, (Kui et al., 2017) use the term" role breadth self-efficacy ", and they defined it as: the confidence to do a variety of tasks beyond the job description.

The data confirm that empowering leadership is positively related to proactive behavior, even after controlling for proactive personality. The researchers also show how this works: sharing power leads to higher role breadth self-efficacy in subordinates, which in turn encourages their proactive behavior. The research additionally shows that the mediating impact of role breadth self-efficacy is stronger when employees have high trust in their leader's competence (Kui et al., 2017).

\subsubsection{Development of Job}

It refers to the perception that the individual has an impact on the core decision-making within the organization. Andrews \& Almaayah (2008) believes that the influence dimension reflects individuals believe they can influence the system in which they work by affecting the system output, and the individual's sense of weakness or lack of his role in influencing the accomplishment of its job leads to job alienation. Rabindra \& Kanungo (1992) confirms that this job alienation has a negative impact on productivity and the quality of working life. In the same direction, William (1992) Indicates that the individual's sense of his inability to influence decisions, leads to a sense of diminishing his role in achieving the organization objectives, and then eventually leads to lack a sense of the individual functional responsibility, low appreciation for himself, and the weakness he felt excited to take the initiative and the risk.

\section{Managerial Creativity}

\subsection{Concept of Managerial Creativity}

Creativity can also be understood as an ideological construct. Zhong and Fan (2016) points out those creative concepts have become the dominant framework in current social and cultural policies, and the main element of 
information theory and the social theory of innovation. Creativity term attributed to the industrial economist Joseph Schumpeter since 1912. He defined creativity as "the production of a new product, the adoption of a new way of working, introduction of new production structures, accessing to new markets, getting access to new production resource. Moore (2014) emphasized that creativity is a widely used concept in many national development strategies. The concept of creative economics is derived from the concept of innovation and is associated with the concept of creativity based on creative industries. The concept of creative industries was first documented in 1994 in Australia when the Australian government issued its new cultural policy, Creative Nation, designed to help Australia embody new IT opportunities with a growing wave of global culture empowered by digital media.

Taylor (1993) found that there is the lack of agreement among researchers on the definition of creativity and so there are several definitions of creativity. From his standpoint, creativity is a change in the output of resources, in the language of economics, mean change in value and satisfaction resulting from the resources used by the consumer. creativity as the optimal use of mental and intellectual capacity, which is characterized by the greatest fluency, flexibility, originality and sensitivity to the problems and the ability to analyze, as leads to the formation of linkages and discover relationships, ideas or new working methods within the administrative organizations.

Creativity is a multi-phased process results in an idea or new work which is characterized by the greatest fluency, flexibility, originality, and sensitivity to the problems, and this ability creative could be developed according to the capabilities and potential of individuals, groups and organizations. Creativity is sensitivity to the problems and the awareness of the weaknesses and gaps and inconsistencies and lack of information and the search for solutions and forecasting process, and the transfer or delivery of the results to others (Torrance, 1993). Managerial creativity is the procedures and processes and behaviors that lead to improve the general climate in the organization and activation of creative performance through motivating employees to solve problems and make decisions in more creative manner and in an unusual way of thinking group.

\subsection{Dimensions of Managerial Creativity}

\subsubsection{Creativity in the Product}

The introduction of new or improved method of production in the enterprise, or the provision of services or delivery of products, which leads to improved product quality or reduce the cost of products. Creativity, in the production method then includes changes in the technique to produce materials from the technical and economic terms, or in production equipment. The aim is to reduce costs to maintain the competitiveness of the organization.

\subsubsection{Marketing Creativity}

It refers to put new ideas in product design, color, branding, pricing, advertising, distribution, customer service, and packaging. It aims to increase sale, increasing the customer confidence and maintain customer loyalty.

\subsubsection{Regulatory Creativity}

This kind of creativity is intangible. It aims to transform and reorganize the management methods and techniques, as well as the knowledge gained to make the organization and the individual behavior more positive and impactive. This kind of creativity require investments in intangible resources by recruiting qualified individuals, in order to strengthen basic skills in the organization, as well as creations in the administration, and that manager often finds it difficult to apply the method of work. According to specialists in quality, about $85 \%$ of the problems that occur in institutions resulting from poor management, and then the improvements that occur in this function can bring a very important added value to Institutions (Bournan \& Bournan, 2009).

\section{Review of Literature}

Turkson and Appiah (2009) found that creativity and innovation are the hub and the fulcrum around which managerial success partly depends. Managers who want to ascend to the top of their chosen profession should lubricate their career path with creative and innovative ideas. Managers who lack creative and innovative ideas are likely to be slaves to conventions and the status quo. The researchers recommended for Refresher courses and other forms of training, and appropriate rewards for managers who introduce creativity and innovation. It should be noted that since creativity and innovation are risky managerial ventures, they should be applied with the appropriate care and caution. Ghorbani and Ahmadi (2011) analyzed the relationship between the dimensions of empowerment and creativity improvement in educational organization of North khorasan. The statistical population covers 130 employees of north khorasan educational organization out of whom 97 employees are selected randomly. The results show that all variables including competence, self-efficiency, autonomy, impact, trust, meaning are related with creativity of employees. Besides, the author suggested that the manager as a 
leader of the organization should try to remove the boundaries which limit the creativity of employees in the organization. Al Zahrani, Zamil, Oraiqat, \& Alsalhi, (2012) examined the impact of employee participation, training and development, organizational culture, incentives, leadership pattern, and teamwork on employees' psychological empowerment. Meaningfulness, competence, self-determination, impact have been used as the proxy variables of psychological empowerment. The paper used multiple regression analyses and empirically tests these hypotheses using a sample of 249 employees working at Jordanian and Saudi industrial corporations. The result showed that all six antecedents of organizational innovation are positively related to psychological empowerment. Besides, $67.2 \%$ of the variation in employees' psychological empowerment is explained by the six antecedents of organizational innovation. At the country level, this study reported that there is no significant difference between the research two-countries of investigation. This may indicates to the high level of awareness towards the importance of antecedents supporting organizational innovation in the surveyed corporations in Jordan and Saudi Arabia. Al-Rousan, Al-Zobaydi \& Al-Haj Hassan (2014) investigated the role of empowerment in different Web-based project development. $76.9 \%$ of the study participants agreed and confirmed it as a best practice. The results proved that the participants working in plan-driven teams are normally the least empowered than participants working in undefined methodology teams. Besides, the participants working in agile teams were the most empowered. Erkutlua and Chafrab (2015) examined the impact of empowerment role identity and creative role identity on servant leadership and employees' innovation implementation behavior. Data was collected through questionnaires from 6 private eye hospitals in Turkey. The sample included 393 office employees and their immediate managers. Moderated hierarchical regression was used to examine the moderating roles of empowerment role identity and creative role identity on the servant leadership and innovation implementation behavior relationship. The results showed that servant leadership is positively and significantly correlated with innovation implementation behavior. In addition, the results of the hierarchical multiple regression analyses support the moderating impacts of empowerment role identity and creative role identity regarding the relationship between servant leadership and innovation implementation behavior. Diab (2017) examined the Impact of empowerment on the organizational creativity among health directors in Jordanian Ministry of Health. The sample consists of (150) Health Managers. Data was collected by questionnaires. Cronbach's alpha was used for the stability of the data and ANOVA and linear regression for testing hypotheses. The study also showed the demographic profile of the respondents. The results highlighted that there is an impact of the management empowerment dimensions (delegation authority, teamwork, training, motivation, and impactive communication) on the health manager's organizational creativity.

\section{Research Methodology}

\subsection{Problem of the Study}

Greater Amman Municipality aspire to be the level of ambition of the country's leadership on the one hand, on the other hand to meet the needs of the residents of the city of Amman, especially with the new circumstances, complex environment, a claim today that is working to raise its capacity to deal with the new challenges faced by the way that guarantees success in planned achieve her goals. By adopting a strategy of Managerial empowerment in a way that allows it to continuous creativity and streaming of high quality and low costs of new services.

From the foregoing, the central idea of this study lies in the need to enhance the managerial creativity of the Greater Amman Municipality to be able to achieve its strategic goals effectively and efficiently.

On the other hand, managerial empowerment is an important topic, it is one of the relatively new fields and complementary to the previous surveys in the literature of business administration. Despite the availability of several studies on the Managerial empowerment and aspects associated with it, but they did not attempt to link the Managerial empowerment with managerial creativity.

Most studies on Managerial empowerment focused on the team rather than the individual level, and did not separate the influence of the leader from the employee's personality, nor was the model that illustrates the relationship between Managerial empowerment and creativity not addressed.

On the practical side, researcher found, during the initial survey, absence of attempts by the management of Greater Amman Municipality regarding the study of the impact of the Managerial empowerment on the managerial creativity, even though it was established since (1938). From this perspective, the researcher determines the problem of the study through the following question: "Are Managerial empowerment affecting managerial creativity in the Greater Amman Municipality?" 


\subsection{Objective of the Study}

The study tries to achieve the following objectives:

-Provide a conceptual framework illustrates the concepts and dimensions of Managerial empowerment and managerial creativity

-Analysis the nature of the impact of Managerial empowerment on managerial creativity Greater Amman Municipality through testing hypotheses.

-Suggesting some future studies that contribute to the promotion of conceptual and practical frameworks of the Managerial empowerment and managerial creativity in general.

\subsection{Importance of the Study}

- Greater Amman Municipality was especially suitable for this study empirical setting because it is an organization where employees' work behaviors are significantly influenced by their leaders.

- Provide a general framework includes dimensions of Managerial empowerment and managerial creativity, and determine the impact between them

- Alert academics who interested in the fields of business management, to the need to strive towards enhancing Managerial empowerment applications as a basis for enhancing managerial creativity.

- Provide an opportunity for researchers to carry out similar studies or efforts to complete this study in the same environment, or in other environments.

\subsection{Study Sample}

The study population was constituted of all the decision makers. So, Regarding the population size (364) decisions makers, an intentional selection of 177 decision makers was chosen in this organization. After a close review (15) questionnaires were refused due to some missing data and unanswered questions. The number of complete and valid questionnaires was 161 , with a response rate of $90 \%$.

\subsection{Questionnaires Design}

The researcher constructed a self-administrated questionnaire to collect and record the information in this study. At the start of the questionnaire, a clear and brief explanation of the survey is pivotal to realizing a positive response from the recipient and hence, improving the response rate as well. The explanation is specifically a justification as to why the researcher wants the impending respondent to complete the survey. The first section of the questionnaire contains some basic information about respondents. The second section included Managerial empowerment items. The third section included managerial creativity items.

\subsection{Conceptual Model of Study}

Figure 1 highlights the conceptual model to explain the relationship between managerial empowerment (independent variable) and managerial creativity (dependent variable). Freedom of choice, self-efficacy, and development of job has been used as the proxy dimensions of managerial empowerment. Besides, creativity in the product, marketing creativity, and regulatory creativity have been used as the proxy dimensions of managerial creativity. The study assumes the existence of a one-way relationship between the two variables.

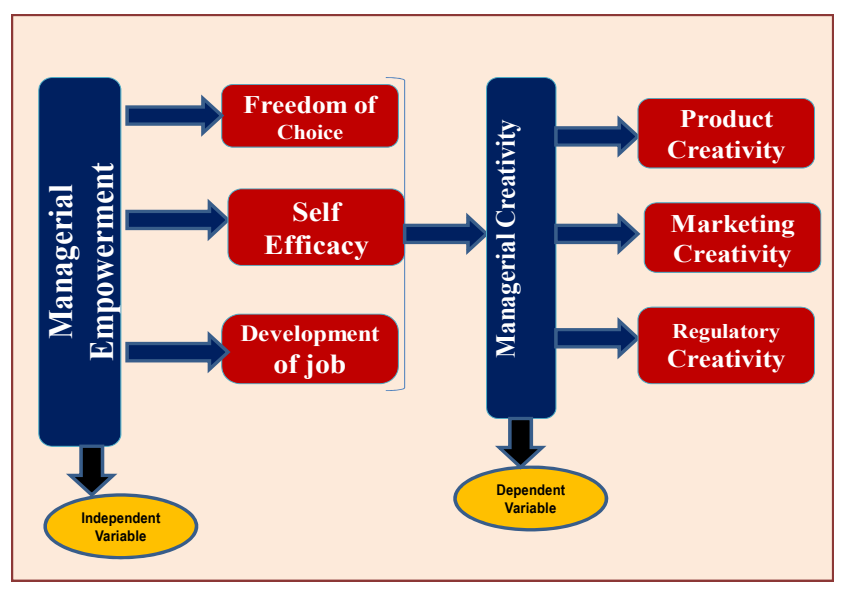

Figure 1. Framework of the research 
Source: The form is designed by the researcher, depending on the following sources.

Diab, S. (2017), Aburuman, Nassem M. (2016), Erkutlua, H., \& Chafrab, J. (2015).

\subsection{Hypotheses of the Study}

$\mathrm{Ho}_{1}$ : There is no statistically significant impact at a significance level $(\alpha=0.05)$ for the managerial empowerment dimensions on the managerial creativity.

$\mathrm{Ha}_{1}$ : There is statistically significant impact at a significance level $(\alpha=0.05)$ for the managerial empowerment dimensions on the managerial creativity.

\section{Test of Data Validity}

The researcher depends on the linear regression analysis to test the research hypothesis. Still, before start using the analysis should test data validity, many conditions allow using the regression analysis. Those conditions check through different analyses as the normal distribution of data, multicollinearity test, and Variance Inflation Factors (VIF). It worth noting the test of validity just for independent variables.

\subsection{Normal Distribution Test}

One of the conditions in using the Linear Regression Test is that data should show normal distribution as indicted by Skewness and Kurtosis. When the Skewness is close to (0) and the Kurtosis is close to (0) or (3); it indicates that data show normal distribution. Table 1 shows the results of the normal distribution of the Independent variables.

Table 1. Normal Distribution of the independent variables

\begin{tabular}{llll}
\hline & creativity in the product & marketing creativity & regulatory creativity \\
\hline Skewness & -0.310 & -0.195 & -0.388 \\
Kurtosis & 3.183 & 2.612 & -2.813 \\
\hline
\end{tabular}

Table 1 explains all independent variables the skewness are close to (0), the variable closest to (0) is marketing creativity (-0.195). On the other hand, all independent variables the kurtosis are close to (3), the closest variable to (3) is Openness experiments. This result indicates that the data show a normal distribution.

\subsection{The Multicollinearity}

It is important to check the multicollinearity problem for continuous and dummy variables before running the model. The variance inflation factors, and tolerance impact were calculated by multiple regression procedures with collinearity diagnostic options. See table 2 .

Table 2. Variance inflation vector

\begin{tabular}{lll}
\hline Variables & VIF & Tolerance impact \\
\hline creativity in the product & 3.528 & 0.283 \\
marketing creativity & 3.298 & 0.303 \\
regulatory creativity & 4.391 & 0.228 \\
\hline
\end{tabular}

From (table 2), we can see all independent variables' tolerance impact is more than (0.1), on the other hand, all VIF less than (10), indicating a lack of multicollinearity within exogenous constructs.

\subsection{Reliability of the Questionnaire}

The instruments were adapted after a careful review of related literature followed by an examination by an expert panel; however, the researcher tries to reaffirm the validity and reliability to a satisfactory degree with the help of internal consistency reliability analysis. Cronbach's alpha coefficient method was selected among the many statistical methods to measure reliability for this research. The lower limit for Cronbach's alpha value is $(0.70)$ according to (Sekaran \& Bougie, 2013). Table 3 shows the reliability of the independent and dependent variables (Cronbach's Alpha).

Table 3. Reliability of the independent and dependent variables (Cronbach's Alpha) 


\begin{tabular}{lll}
\hline Variables & Statement & Cronbach's Alpha \\
\hline Freedom of choice & 5 & 0.832 \\
self-efficacy & 5 & 0.861 \\
development of job & 5 & 0.866 \\
creativity in the product & 7 & 0.823 \\
marketing creativity & 7 & 0.805 \\
regulatory creativity & 4 & 0.875 \\
All items & 33 & 0.913 \\
\hline
\end{tabular}

From the table 3, we can see that all the study variables' reliability Cronbach's alpha values are more than (0.7). The highest Cronbach's alpha value $(0.875)$ belongs to the "regulatory creativity" variable, while the lowest $(0.805)$ belongs to the "marketing creativity" variable. All items' Coefficient Cronbach's Alpha is (0.913). Therefore, the study results can be accepted.

\section{Test the Hypothesis}

"There is no statistically significant impact at a significance level $(\alpha=0.05)$ for the managerial empowerment dimensions on the managerial creativity". To test this hypothesis, the study used multiple linear regression analysis. Table (4) and (5) illustrate the results of this test:

Table 4. Analysis of variance (ANOVA) to test the validity of the multiple linear regression models to test the hypothesis of the study

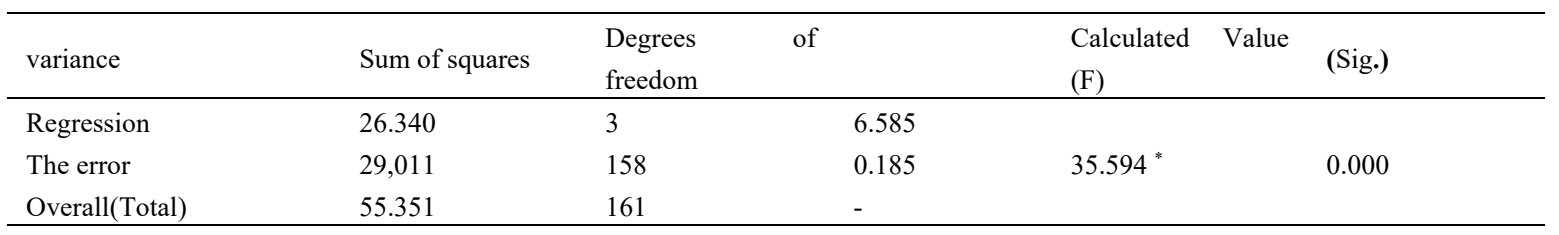

Since the calculated (F) value (35.594) is greater than the Tabulated (F) value (2.37), as well as the value of statistical significance (Sig) amounting to (0.000) which is lower than the level of significance $(\alpha=0.05)$ it will reject the null hypothesis, this means proven validity of the model, and therefore, the independent variables (Freedom of choice, Self-efficacy, Meaning, Development of Job) impact on the managerial Creativity

Table 5. The results of multiple linear regression analysis, to measure the impact of the managerial empowerment dimensions on Managerial Creativity

\begin{tabular}{llll}
\hline Variables & Regression coefficients $(\boldsymbol{\beta})$ & Calculated Value $(\mathrm{t})$ & $\mathbf{( S i g . )}$ \\
\hline Constant $\left(\boldsymbol{\beta}_{\mathbf{0}}\right)$ & 0.042 & 0.079 & 0.937 \\
Freedom of choice & 0.402 & 7.498 & 0.000 \\
Self-efficacy & 0.283 & 3.871 & 0.000 \\
Development of Job & 0.036 & 0.481 & 0.631 \\
Multiple correlation coefficient $(\mathbf{R})$ & 0.690 & & \\
Debugger interpretation coefficient $\left(\mathbf{R}^{2}\right)$ & 0.463 & & \\
\hline
\end{tabular}

\section{Discussion}

- Regression coefficients $(\beta)$, are significant for the dimensions (Freedom of choice and Self-efficacy), so there is a statistically significant impact at a significance level $(\alpha=0.05)$ for the mentioned dimensions on the Creativity, What is supported by the calculated $(t)$ values for these two dimensions $(7.498,3.871)$, respectively, as well as the statistical significance of the values of (Sig.) for these dimensions less than the level of significance $(\alpha=0.05)$. In light of previous results will be rejected the null hypothesis and accept the alternative hypothesis, which states: There is a statistically significant impact at a significance level $(\alpha=0.05)$ for the dimensions of the managerial empowerment on the managerial creativity.

- The value of multiple correlation coefficient $(\mathrm{R})$ was $(0.690)$, indicating that there is a medium strength and positive relationship (proportional) and statistically significant at a significance level $(\alpha=0.05)$, between 
managerial creativity and the managerial empowerment dimensions (Freedom of choice, Self-efficacy).

- The value of the debugger explanation coefficient $\left(\mathrm{R}^{2}\right)$ that equal to $(0.463)$ indicates that the dimensions (Freedom of choice, Self-efficacy), interprets about (46.3\%) of the changes in the Creativity, while the remainder, amounting to $(53.7 \%)$, are attributable to other variables not included in the multiple linear regression model.

-Regression coefficients $(\boldsymbol{\beta})$, are not significant for (Development of Job) dimension, so there is no a statistically significant effect at a significance level $(\alpha=0.05)$ for this dimension on the Creativity in the product, What is supported by the calculated ( $\mathrm{t}$ value for this dimension $(0.481$,$) , , as well as the statistical significance of the$ value of (Sig.) for this dimension more than the level of significance $(\alpha=0.05)$. Considering previous results will be accepted the null hypothesis and reject the alternative hypothesis partially

the Results of the study showed a statistically significant impact of the managerial empowerment dimensions (Freedom of choice, Self-efficacy) on the managerial creativity in the Greater Amman Municipality, it is clear from the previous result that increased awareness of the Greater Amman Municipality Administration, will contribute significantly to strengthening the managerial creativity. This result is supported by the arguments and the findings of Diab (2017), Erkutlua and Chafrab (2015), Al-Rousan, Al-Zobaydi \& Al-Haj Hassan (2014), Al Zahrani, Zamil, Oraiqat, and Alsalhi, (2012), Ghorbani and Ahmadi (2011) Whose results all emphasized the existence of a relationship and an impact of managerial empowerment on the managerial creativity.

\section{Conclusion}

Managerial empowerment is a technique for managing HR that help to exploit the potential of employees and self-motivate them by providing certain elements in their jobs, such as the meaning, power, and influence. It is the management style, through which managers and other organizational members share to influence the decision-making process. The vision of empowerment is to develop a strong and capable workforce with a productive capacity for services and goods that exceed consumer expectations. Managerial creativity is the procedures and processes and behaviors that lead to improve the general climate in the organization and activation of creative performance through motivating employees to solve problems and make decisions in more creative manner and in an unusual way of thinking group. The aim of this empirical study has been to examine the current state of managerial empowerment and its impact on managerial Creativity in Greater Amman Municipality. The results showed that Greater Amman Municipality has adopted managerial empowerment applications, but the adoption level was not high, as they have only adopted basic applications. The finding implied that more efforts are needed to help and encourage Greater Amman Municipality leaders to enhance managerial empowerment adoption, particularly Self-efficacy, and freedom of choice. In addition to this, the results of the study showed a statistically significant impact of the managerial empowerment dimensions self-efficacy and freedom of choice on the managerial creativity in Greater Amman Municipality. It is clear from the previous result that increased awareness of the Greater Amman Municipality Administration, will contribute significantly to strengthening the managerial creativity.

\section{Recommendations}

1- Develop managerial empowerment strategy and their applications to be a bases relied upon when the Greater Amman Municipality initiative to implement the managerial empowerment programs under the general strategy of the organization by building a full conviction in the various administrative levels about benefits and positive effects achieved by managerial empowerment, particularly with regard to the promotion of managerial creativity.

2- Disseminate the results of the implementation of the managerial empowerment initiatives in some public and private organizations, with the aim of expanding and strengthening other organizations realize the benefits of managerial empowerment, so these results become lessons can be utilized in subsequent experiments.

3-The need for future studies on other variables, different from the variables covered by the study, with the use of other statistical indicators to address the data of the study that will be conducted in the future.

Acknowledgement: I am thankful to Prof. Mohammed for his valuable suggestions received while compiling this research article. This article has been funded by Zarqa University, Jordan.

\section{References}

Aburuman, N. M. (2016). The Impact of Administrative Empowerment on Creativity Improvement among the Workers of Jordanian Public Administration Institute. International Journal of Business and Social Science, $7(1)$.

Amabile, T. M., Schatzel, E. A., Moneta, G. B., \& Kramer, S. J. (2004), Leader behaviors and the work 
environment for creativity: Perceived leader support. Leadership Quarterly, 15, 5-32.

Al Zahrani, A. A., Zamil, A. M., Oraiqat, A. Y. M., \& Alsalhi, N. (2012). The impact of antecedents supporting organizational innovation on employees' psychological empowerment: An empirical study of Saudi and Jordanian industrial corporations. African Journal of Business Management, 6(24), 7329-7343. https://doi.org/10.5897/AJBM11.3032

Cattaneo, L. B., \& Chapman, A. (2010), The Process of Empowerment A Model for Use in Research and Practice. American Psychologist, 65(7).

Diab, S. (2017). The Impact of Empowerment on the Organizational Creativity among Health Directors in the Jordanian Ministry of Health (An Empirical Study). International Journal of Academic Research in Business and Social Sciences, 7(12), 821. http://dx.doi.org/10.6007/IJARBSS/v7-i12/3715

Erkutlua, H., \& Chafrab, J. (2015). The impacts of empowerment role identity and creative role identity on servant leadership and employees' innovation implementation behavior. Retrieved from https://cyberleninka.org/article/n/406609

Gheian, A. L., \& Gal, J. H. (2017). Delegation of Responsibilities and Decision-Making Authority in a Low Trust Country. Bachelor Thesis in Business Administration.

Ghorbani, M., \& Ahmadi, S. (2011). Relationship between employee's empowerment dimensions and creativity improvement in educational organizations. Middle East Journal of Scientific Research, 10(2), 213-217.

Jung D. I., Chow, C., \& Wu A. (2003). The role of transformational leadership in enhancing organizational innovation: hypotheses and some preliminary findings. Leadership Quarterly, 14, 525-44.

Kahai, S. S., Sosik, J. J., \& Avolio, B. J. (2003). Impacts of leadership style and problem structure on work group processes and outcomes in an electronic meeting system environment. Personnel Psychology, 50, 121-146.

Sekaran, U., \& Bougie, R. (2013). Research Methods for Business: A Skill-Building Approach.

Shin, S., \& Zhou, J. (2003), Transformational leadership, conservation, and creativity: Evidence from Korea. Academy of Management Journal, 46, 703-714.

Srivastava, A., Bartol, K., \& Locke, E. (2006). Empowering leadership in management teams: Impacts on knowledge sharing, efficacy, and performance. Academy of Management Journal, 49(6), 1239-1251.

Shipton, H., West, M. A., Dawson, J., Birdi, K., \& Patterson, M. (2006). HRM as a predictor of innovation. Human Resource Management Journal, 16(1), 23-27.

Turkson, J. K., \& Appiah, K. O. (2009). Managerial Creativity and Innovation: A Panacea for Organizational Change and Development. Global Business and Economics Anthology, 2, 117-122.

Thamer, A. R. A., \& Al-Zobaydi, O. A. H. H. (2014). The roles of decision making and empowerment in Jordanian web-based development organisations. Journal of Web Engineering, 13(5\&6), 469-482.

Zhang, X., \& Bartol, K. M. (2010), Linking empowering leadership and employee creativity: The influence of psychological empowerment, intrinsic motivation and creative process engagement. Academy of Management Journal, 53(1), 107-128.

Zhang, X. M., \& Zhou, J. (2014). Empowering leadership, uncertainty avoidance, trust, and employee creativity: Interaction impacts and a mediating mechanism. Organizational Behavior and Human Decision Processes; 124(2).

Zhou, J., \& George, J. M. (2001). When job dissatisfaction leads to creativity: Encouraging the expression of voice. Academy of Management Journal, 44, 682-696.

\section{Copyrights}

Copyright for this article is retained by the author(s), with first publication rights granted to the journal.

This is an open-access article distributed under the terms and conditions of the Creative Commons Attribution license (http://creativecommons.org/licenses/by/4.0/). 